\title{
Co-registration of 3D echo and MR data to create physical models of congenital heart malformations
}

\author{
Tyler Moore ${ }^{3 *}$, Erin J Madriago ${ }^{1}$, Eric S Renteria ${ }^{2}$, Cristina Fuss ${ }^{3}$, David J Sahn ${ }^{1}$, Del Shepard ${ }^{1}$, Michael Silberbach ${ }^{1}$ \\ From 18th Annual SCMR Scientific Sessions \\ Nice, France. 4-7 February 2015
}

\section{Background}

MR reconstruction of virtual 3 dimensional volumes are routinely used to demonstrate cardiac malformations, particularly the complex geometric relationships between the great arteries and cardiac chambers. However, because of the need to signal average over multiple heart beats, rendering fast moving structures such as atrioventricular (AV) and semilunar valves has been limited. Echocardiography has sufficient frame rates to acquire images of moving valves in real-time $3 \mathrm{~d}$ volumes.

\section{Methods}

We used state-of-the-art commercially-available computer software (Mimics Innovation Suite v17.0, Materialise, Belgium) to develop an efficient work flow that permits importation of $3 \mathrm{~d}$ echo data and co-registration with MR cardiac angiograms. The AV valve plane is localized using single-shot BFFE pulse sequences prior to MR angiography. After the MR acquisition, an echocardiographic $3 \mathrm{~d}$ volume of the moving AV valve is acquired (Philips Ie 33 Echo machine, $x 7-2$ matrix $3 \mathrm{~d}$ probe) and exported to Mimics as DICOM files, 30 phases and 208 slices/phase. Visual inspection of thumbnail images allows phase selection of the fully open valve. Point-topoint registration between the echo-derived AV valve anulus and the MR-derived AV valve plane permits coregistration with the whole heart angiogram. STL files are exported for $3 \mathrm{~d}$ printing.

${ }^{3}$ Department of Radiology, Oregon Health \& Sciences University, Portland, OR, USA

Full list of author information is available at the end of the article

\section{Results}

We have successfully combined $3 \mathrm{~d}$ echo and MR data to create a physical model in order to plan the operative approach for a 2.5 year old child with single ventricle and single AV valve.

\section{Conclusions}

Echocardiographic and cardiac MR imaging technologies each have unique advantages that, until now, have been relegated to separate spheres of diagnostic imaging. Integrating these two modalities to create physical models of complex cardiac malformations will give cardiothoracic surgeons and cardiologists a powerful new tool to plan interventions.

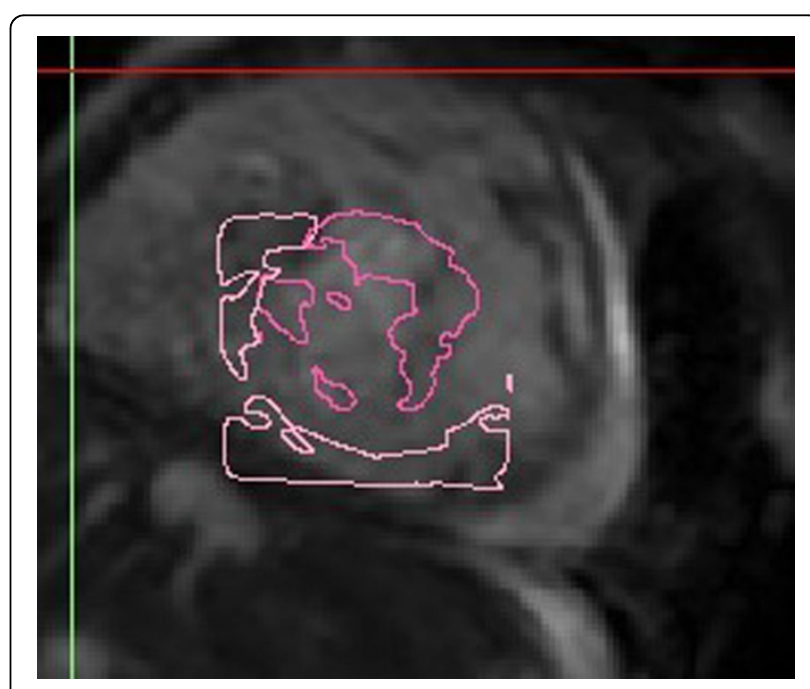

Figure 1 MR AV valve plane and Echo valve outline. 


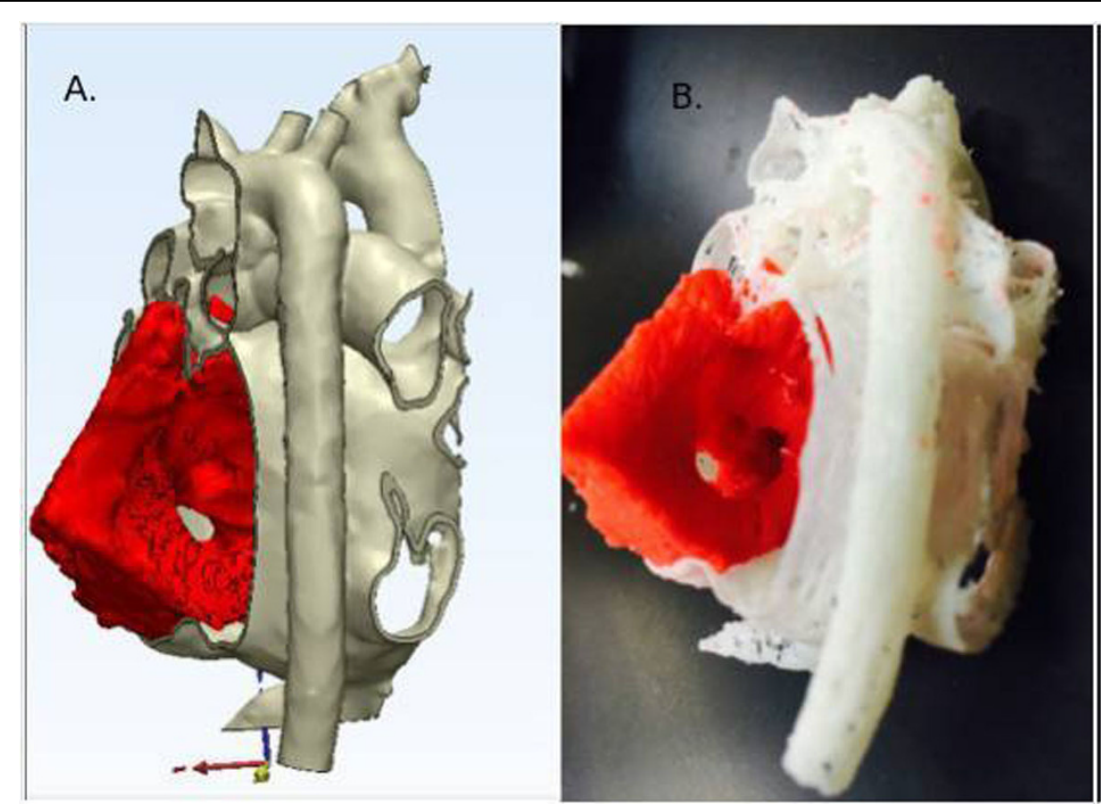

Figure 2 Integrated 3d Echo (red) and MR angiography (white/gray): A. Mimics virtual rendering. B. Physical model (MakerBot Industries, Brooklyn NY).

\section{Funding}

Friends of Doernbecher Children's Hospital.

\section{Authors' details}

'Division, Pediatric Cardiology, Oregon Health \& Sciences University,

Portland, OR, USA. ${ }^{2}$ Innovation Suite, Applications Engineer, Materialise,

Plymouth, MI, USA. ${ }^{3}$ Department of Radiology, Oregon Health \& Sciences

University, Portland, OR, USA.

Published: 3 February 2015

doi:10.1186/1532-429X-17-S1-P198

Cite this article as: Moore et al:: Co-registration of 3D echo and MR

data to create physical models of congenital heart malformations.

Journal of Cardiovascular Magnetic Resonance 2015 17(Suppl 1):P198.

\section{Submit your next manuscript to BioMed Central} and take full advantage of:

- Convenient online submission

- Thorough peer review

- No space constraints or color figure charges

- Immediate publication on acceptance

- Inclusion in PubMed, CAS, Scopus and Google Scholar

- Research which is freely available for redistribution 